\title{
FAKTOR-FAKTOR YANG MEMPENGARUHI WORD OF MOUTH PADA NASABAH BANK
}

\author{
DEWI KARLINA \\ DENNY SEPTA HARYANTI \\ Trisakti School of Management, Jl. Kyai Tapa No. 20, Jakarta, Indonesia \\ dewikarlina26@gmail.com
}

\begin{abstract}
The purpose of this study is to know how the influence of Service Quality, Perceived Value, and Convenience to Word of Mouth in Mandiri Syariah Bank Jakarta Kedoya Branch and Jakarta Tanjung Duren Branch.The research design used in descriptive research and causality research. The sampling used in this research is nonprobability sampling by purposive sampling methods and will require 152 respondents. The respondents must be the customer in Mandiri Syariah Bank Jakarta Kedoya Branch and Jakarta Tanjung Duren Branch. The research data is processed with IBM Statistic 23 as a tool.The result showed that service quality have an impact to word of mouth. Perceived value have no impact to word of mouth. Convenience have an impact to word of mouth.
\end{abstract}

Keywords: Keywords: service quality, perceived value, convenience, word of mouth

Abstrak: Tujuan penelitian adalah untuk mengidentifikasi dan menganalisis Pengaruh Service Quality, Perceived Value, Convenience, terhadap Word of Mouth di bank Mandiri Syariah cabang KCP Jakarta Kedoya dan KCP Jakarta Tanjung Duren. Teknik sampling yang digunakan pada penelitian ini adalah nonprobability sampling dengan metode purposive sampling dan akan membutuhkan 152 responden. Responden merupakan nasabah Bank Mandiri Syariah KCP Jakarta Kedoya dan KCP Jakarta Tanjung Duren. Penelitian ini menggunakan metode statistik dengan programIBM statistic 23 sebagai alat ujinya. Hasil dari penelitian ini menunjukkan terdapat pengaruh service quality terhadap word of mouth. Tidak terdapat pengaruh perceived value terhadap word of mouth. Terdapat pengaruh convenience terhadap word of mouth.

Kata kunci: Service quality, perceived value, convenience, word of mouth

\section{PENDAHULUAN}

Indonesia merupakan negara yang memiliki banyak keragaman dari budaya, suku bangsa, agama, hingga aliran-aliran kepercayaan. Indonesia juga merupakan negara kepulauan terbesar di dunia dengan jumlah pulau sebanyak 16.056 pulau dan penduduk sebanyak 261.890 .900 pada tahun 2017 (Badan Pusat Statistik: Penduduk
Menurut Provinsi, Kewarganegaraan dan Jenis Kelamin).Salah satu indikator untuk melihat kondisi ekonomi suatu negara pada periode waktu tertentu adalah dengan data Produk Domestik Bruto (PDB).

Berdasarkan Tabel 1.1 diatas dapat di ketahui bahwa PDB Indonesia tahun 2016, 2017, dan 2018 mengalami stagnan walaupun sempat turun di tahun 2017 sebesar 0.10 persen menjadi 5.07 persen. Hal ini disebabkan 
karena tidak semua industri lapangan usaha di Indonesia mengalami peningkatan, tetapi ada juga yang mengalami penurunan. Terjadinya penurunan pada tahun 2017 disebabkan melambatnya 11 sektor diantaranya adalah sektor Pengadaan Listrik dan Gas, Pertanian, Kehutanan dan Perikanan, Jasa Pendidikan, Perdagangan Besar dan Eceran, Pengadaan Air, Industri Pengolahan, Jasa Kesehatan, Administrasi Pemerintah, Jasa Keuangan dan Jasa Perusahaan, penurunan terbanyak yaitu pada sektor Administrasi Pemerintahan sebesar 4.96 persen juga di sektor Pengadaan Listrik dan Gas sebesar 3.93 persen.

Namun di tahun 2018 laju pertumbuhan PDB Indonesia kembali mengalami peningkatan sebesar 0.10 persen menjadi 5.17 persen disebabkan adanya beberapa sektor industri yang mengalami peningkatan, yaitu pada industri Penyediaan Akomodasi dan Makan Minum sebesar 0.27 persen menjadi 5.66 persen dan Jasa Pendidikan dengan 5.36 persen, Pengolahan Non Migas dengan 4.77 persen, Perdagangan Besar dan Eceran dengan 4.97 persen, Real Estate dengan 3.58 persen bahkan melewati nilai rata-rata dari Produk Domestik Bruto (PDB) Indonesia pada tahun 2018 yang memiliki nilai sebesar 5.17 persen. Walaupun terjadi penurunan di beberapa sektor seperti salah satunya Sektor Jasa Keuangan disini penulis berharap dapat membantu pemerintah dalam mengembangkan dan meningkatkan sektor sektor yang mengalami penurunan khususnya di sektor Jasa Keuangan.

Di era modern saat ini istilah bank sudah tidak asing lagi terdengar di telinga kita. Salah satu faktor penting dalam pertumbuhan ekonomi khususnya disektor Jasa Keuangan adalah bagaimana berkembangannya dunia perbankan di Indonesia. Bank merupakan sebuah lembaga roda perekonomian dan sebagai jasa pelayanan dimana masyarakat dapat melakukan berbagai transaksi finansial didalam aktifitas perekonomian masyarakat
Indonesia. Ada nya sebuah bank memudahkan masyarakat yang produktif mendapatkan dana untuk suatu usaha, sehingga masyarakat yang awalnya menganggur bisa mendapatkan pekerjaan dan mengurangi tingkat kemiskinan. Selain itu kemudahan dan keamanan membuat masyarakat semakin percaya pada sektor perbankan.

Bank didirikan sebagai lembaga intermediasi yang menghimpun dana dari masyarakat dan menyalurkan ke masyarakat pula. Bank juga merupakan perantara antara orang-orang yang kelebihan dana dan dengan orang-orang yang kekurangan dana. Tujuan dari kegiatan ini adalah dalam rangka meningkatkan taraf hidup rakyat banyak.

Di Indonesia sendiri, dalam dunia perbankan, dikenal dua jenis bank yaitu Bank Konvensional dan Bank Syariah. Masyarakat Indonesia masih belum banyak mengetahui perbedaan di antara keduanya, perbedaan keduanya pun cukup beragam. Bank konvensional adalah bank yang melaksanakan kegiatan usaha secara konvensional yang dalam kegiatannya memberikan jasa dalam lalu lintas pembayaran secara umum berdasarkan prosedur dan ketentuan yang telah ditetapkan oleh Negara. Bank konvensional akan menerima segala macam bentuk investasi kesemua bidang usaha asalkan sesuai dengan persyaratan yang telah ditetapkan.

Bank konvensional hanya berorientasi pada keuntungan, menetapkan bunga sebagai harga, dan untuk jasa-jasa bank lainnya, pihak bank menggunakan atau menerapkan berbagai biaya dalam nominal atau presentase tertentu. Sedangkan, Bank Syariah adalah suatu sistem perbankan yang pelaksanaannya berdasarkan hukum islam (syariah).

Dalam penelitian ini, peneliti memilih objek penelitian yaitu PT Bank Syariah Mandiri. PT Bank Syariah Mandiri secara resmi mulai beroperasi sejak tanggal 1 November 1999. PT Bank Syariah Mandiri hadir dan tampil dengan 
harmonisasi idealisme usaha dengan nilai-nilai spiritual.

Pada tabel 1.2 bisa dilihat bahwa Bank Mandiri Syariah berada di peringkat pertama Top Brand Award, namun mengalami penurunan presentase pada tahun 2017 dan mulai mengalami kenaikan kembali pada tahun 2018. Hal ini dikarenakan tingkat persaingan yang semakin ketat antar Bank Syariah di Indonesia.

Akan tetapi walaupun menduduki peringkat pertama Top Brand Award, bank Mandiri tetap memiliki beberapa permasalahan yang terjadi akhir-akhir ini seperti salah satu contohnya, yaitu hilangnya saldo nasabah akibat terjadi kerusakan sistem di bank Mandiri, rata-rata saldo yang hilang dari rekening mereka sebesar 10 persen. Akibat kejadian ini tingkat kepercayaan nasabah terhadap bank Mandiri berkurang, karena nasabah merasa kecewa terhadap kenyamanan dalam menyimpan uangnya di bank Mandiri (menurut kompas.com).

Hal ini berdampak terhadap anak perusahaan bank Mandiri terutama bank Mandiri Syariah. Sesuai dengan variabel yang diteliti, bank Mandiri Syariah harus meningkatkan kembali kepercayaan nasabah yaitu dengan cara menciptakan kenyamaan, nilai dan citra yang baik bank Mandiri Syariah terhadap nasabah.

Selain itu permasalahan yang terjadi pada Bank Mandiri Syariah lainnya adalah dapat dilihat pada tabel 1.4 dimana bank Mandiri Syariah ditahun 2018 memiliki selisih dengan BRI Syariah hanya sebesar 0,1\%. Hal ini merupakan ancaman untuk bank Mandiri Syariah dimana tidak menutup kemungkinan bahwa BRI Syariah dapat mengungguli bank Mandiri Syariah di tahun berikutnya. Berdasarkan masalah yang terjadi bagaimanakah Bank Mandiri Syariah dapat mempertahankan posisinya sebagai Top Brand bank Syariah di Indonesia ditahun tahun berikutnya sehingga tetap menjadi Bank Syariah yang unggul di bandingkan dengan
pesaingnya.Hal ini mendorong peneliti ingin mengetahui penyebab gap tersebut serta dampak terhadap nasabah berdasarkan variabel-variabel terkait, terutama dalam meneliti Convenience melalui Perceived Value tehadap Word of Mouth di bank Mandiri Syariah.

\section{Service Quality}

Menurut Akroush dan Mahadin (2017) mendefiniskan service quality sebagai berikut "Service quality is the firms' ability to deliver services in accordance with customer's level of expectation."

Menurut Kotler dan Keller $(2017,156)$ "Service quality is any act of performance that one party can offer to another that is essentially intangible and does not result in the ownership of anything".

Kotler dan Amstrong (2014, 264) berpendapat tentang service quality "service firm can differentiate itself by delivering consistenly higher quality than is competitors provide".

Chaffey dan Chadwick (2012, 669) menyatakan "Service quality is the level of service received on a website. Dependent on reliability, responsiveness and availability of staff and te website service".

Berdasarkan beberapa definisi diatas, dapat disimpulkan bahwa service quality adalah karakteristik sebuah layanan yang disampaikan guna mencapai kepuasan konsumen.

Menurut Akroush dan Mahadin (2017) menyatakan bahwa dimensi service quality sebagai berikut: menyediakan layanan dengan cepat dan mahir, selalu siap menangani permintaan dan kebutuhan pelanggan, menjaga kerahasiaan dan privasi pelanggan, selalu bersedia membantu pelanggan, memiliki layanan e-banking yang mudah d gunakan.

\section{Perceived Value}

Menurut Akroush dan Mahadin (2017) mendefiniskan Perceived Value sebagai berikut perceived value, it is the perception created by 
customers about their interaction with service providers."

Menurut Grewal dan Levy $(2015,353)$ "the perceived value of brand is the relationshop between a product's or service's benefits and its cost". Maksudnya adalah perceived value adalah hubungan antara manfaat produk atau jasa dengan harganya.

Kotler Keller (2016:151) mendefinisikan perceived value sebagai "the difference between the prospective customer's evaluation of all the benefits and all the costs of an offering and the perceived alternatives. Jadi dapat digambarkan bahwa Perceived Value merupakan pandangan pelanggan mengenai keuntungan yang akan iya dapatkan dan semua biaya yang ditawarkan serta alternatif yang dapat dimiliki dengan menggunakan produk atau jasa yang kita tawarkan.

Berdasarkan beberapa definisi di atas, maka perceived value dapat disimpulkan sebagai penilaian konsumen secara keseluruhan terhadap manfaat produk yang dimiliki dan diperoleh dan didasarkan dari apa yang mereka terima dan apa yang mereka berikan.

Menurut Akroush dan Mahadin (2017) menyatakan bahwa dimensi perceived value sebagai berikut:puas dengan layanan yang diterima, layanan yang adil berdasarkan hukum Islam, kinerja yang sesuai dengan harga yang dibayar.

\section{Convenience}

Menurut Akroush dan Mahadin (2017) mendefiniskan convenience sebagai berikut "Convenience is the ability to reduce consumers non-monetary costs (i.e. time, energy and effort) when purchasing or using goods and services."

Menurut Lai et al (2007) "convenience is a proposition of value expressed by the moment of truth which can be used interchangeably as service encounter" Menurut Berry et al. (2002) menyatakan convenience adalah "consumers" time and effort perceptions related to buying or using a service."

Menurut Chang and Polonsky (2012) menyatakan concenience adalah "ability to reduce consumers non-monetary cost (i.e. time, energy and effort) when purchasing or using goodsand services."

Dari definisi diatas dapat disimpulkan bahwa kenyamanan merupakan suatu perasaan seseorang, dari yang paling nyaman dengan yang paling tidak nyaman, yang dirasakan secara langsung maupun tidak langsung oleh seorang individu yang dimana kenyamanan bagi seorang individu tertentu belum tentu individu lain juga akan merasakan kenyamanan tersebut.

Menurut Akroush dan Mahadin (2017) menyatakan bahwa dimensi religious motives sebagai berikut dekat dengan tempat tinggal, dekat dengan tempat kerja, memiliki cabang yang banyak, memiliki penampilan dan desain yang baik.

Menurut Akroush dan Mahadin (2017) menyatakan bahwa dimensi perceived value sebagai berikut puas dengan layanan yang diterima, layanan yang adil berdasarkan hukum Islam, kinerja yang sesuai dengan harga yang dibayar.

\section{Word Of Mouth}

Menurut Akroush dan Mahadin (2017) mendefiniskan word of mouth sebagai berikut"WOM is an important element of the Iranian banks competitive advantage, in addition to factors such as corporate image, relationship marketing, perceived value, perceived risk, satisfaction and loyalty which are found to be the major determinants of positive WOM."

Menurut Hogan et al (2004), "WOM is believed to be able to complement and extend the effect of advertising" Menurut Anderson (1998, p. 6), Word-of-mouth (WOM) didefinisikan sebagai "informal communication 
between private parties concerning evaluations of goods and services"

$$
\text { Menurut Keller (2016, 246) }
$$
menyatakan bahwa Word of Mouth sebagai berikut "WOM is a critical aspect of brand building consumers share their likes, dislike, and experiences with brands with each other". Dimana Word of Mouth adalah aspek kritis dari brand building dimana konsumen berbagi pendapat mengenai suka, tidak suka dan pengalaman yang di terima satu merek dengan merek lainnya.

Dari definisi word of mouth diatas dapat disimpulkan bahwa word of mouth merupakan media promosi baik secara lisan, tulisan dan alat komunikasi elektronik di mana konsumen memberikan informasi mengenai suatu merek atau produk kepada konsumen lain dan menyebarkan kepada konsumen lainnya.

Menurut Akroush dan Mahadin (2017) menyatakan bahwa dimensi Word of Mouth sebagai berikut: merekomendasikan layanan kepada teman, merekomendasikan layanan kepada keluarga dan kerabat, merekomendasikan layanan melalui media massa.

\section{METODE PENELITIAN}

Metode penelitian yang digunakan dalam penelitian ini adalah penelitian deskriptif dan kausalitas karena bertujuan mengetahui pengaruh service quality, religious motives, dan convenience melalui perceived value terhadap word of mouth pada Bank Mandiri Syariah.

Objek dalam penelitian ini adalah responden yang merupakan nasabah Bank Mandiri Syariah. Responden dalam penelitian ini adalah nasabah Bank Mandiri Syariah.

Objek yang dipilih dalam penelitian ini yaitu objek yang termasuk dalam kriteria sebagai berikut: Responden merupakan nasabah Bank Mandiri Syariah KCP Jakarta Kedoya atau Bank Mandiri Syariah Cabang Jakarta Tanjung Duren, Responden sudah menjadi nasabah Bank Mandiri Syariah KCP Jakarta Kedoya atau Bank Mandiri Syariah Cabang Jakarta Tanjung Duren selama minimal 1 tahun, Responden aktif bertransaksi pada Bank Mandiri Syariah KCP Jakarta Kedoya atau Bank Mandiri Syariah Cabang Jakarta Tanjung Duren dalam kurun waktu 3 bulan terakhir.

HASIL

Tabel 1 Hasil Uji Validitas

\begin{tabular}{ccccc}
\hline Variabel & $\begin{array}{c}\text { Item } \\
\text { Pertanyaan }\end{array}$ & r hitung & $\begin{array}{c}\mathbf{r} \text { tabel } \\
(\mathbf{d f}=\mathbf{n}-(\mathbf{k}+\mathbf{1}))\end{array}$ & Keterangan \\
\hline Service Quality & SQ1 & 0,617 & 0,1678 & valid \\
& SQ2 & 0,638 & 0,1678 & valid \\
& SQ3 & 0,789 & 0,1678 & valid \\
& SQ4 & 0,681 & 0,1678 & valid \\
Perceived Value & SQ5 & 0,310 & 0,1678 & valid \\
& PV1 & 0,910 & 0,1678 & valid \\
Convenience & PV2 & 0,540 & 0,1678 & valid \\
& PV3 & 0,924 & 0,1678 & valid \\
& C1 & 0,680 & 0,1678 & valid \\
& C2 & 0,566 & 0,1678 & valid \\
Word Of Mouth & C3 & 0,853 & 0,1678 & valid \\
& C4 & 0,853 & 0,1678 & valid \\
& WOM1 & 0,784 & 0,1678 & valid
\end{tabular}




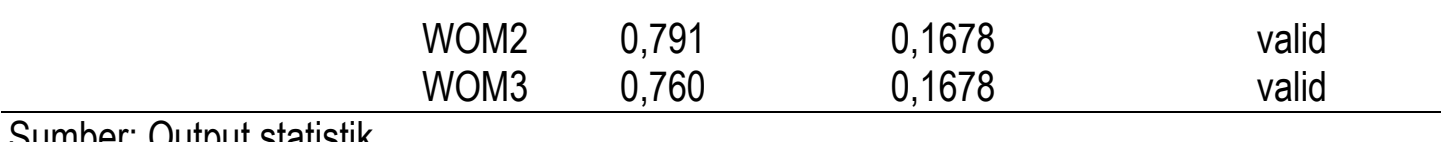

Sumber: Output statistik

Tabel 2 Hasil Uji Reliabilitas

\begin{tabular}{ccccc}
\hline Variabel & $\begin{array}{c}\text { Jumlah } \\
\text { Pertanyaan }\end{array}$ & $\begin{array}{c}\text { Cronbach } \\
\text { Alpha }\end{array}$ & Batas $=\mathbf{0 , 6 0}$ & Keterangan \\
\hline Service Quality (X1) & 5 & 0,745 & 0,60 & Reliabel \\
Perceived Value (X2) & 3 & 0,830 & 0,60 & Reliabel \\
Convenience (X3) & 4 & 0,794 & 0,60 & Reliabel \\
Word Of Mouth (Y) & 3 & 0,816 & 0,60 & Reliabel \\
\hline
\end{tabular}

Sumber: Output statistik

Pada tabel di atas dapat dapat dilihat bahwa semua variabel independen (Service Quality, Perceived Value, Convenience) dan variabel dependen (Word Of Mouth) mempunyai nilai $r$ hitung lebih besar dari $r$ tabel, sehingga dapat disimpulkan bahwa butir pertanyaan kuesioner valid untuk mengukur apa yang seharusnya diukur.
Pada tabel di atas dapat dilihat bahwa semua variabel independen (Service Quality, Perceived Value, Convenience) dan variabel dependen (Word Of Mouth) mempunyai nilai Cronbach alpha lebih besar dari 0,60 sehingga dapat disimpulkan kuesioner reliabel yang artinya dapat menghasilkan jawaban yang konsisten dari waktu ke waktu.

Tabel 3 Uji Normalitas Kolmogorv-Smirnov

\begin{tabular}{ccc}
\hline Asymp.sig (2-tailed) & Alpha & Keterangan \\
\hline 0,298 & 0,05 & Normal \\
\hline
\end{tabular}

Sumber: Output statistik

Pada tabel di atas hasil uji normalitas dengan metode Kolmogorov-smirnov diperoleh nilai asymp.sig (2-tailed) sebesar 0,298 yang berarti lebih besar dari nilai alpha 0,05, sehingga dapat disimpulkan bahwa data berdistribusi normal.

Tabel 4 Hasil Uji Multikolinearitas

\begin{tabular}{lll}
\hline & \multicolumn{2}{l}{ Collinearity Statistics } \\
\cline { 2 - 3 } Model & Tolerance & VIF \\
\hline $1 \quad$ Total SQ & .531 & 1.884 \\
Total PV & .591 & 1.691 \\
Total C & .801 & 1.248 \\
\hline
\end{tabular}

Sumber: Output statistik

Pada tabel di atas dapat dilihat bahwa semua variabel independen (Service Quality, Perceived Value, Convenience) dan variabel dependen (Word Of Mouth) memiliki nilai tolerance lebih besar dari 0,1 dan nilai VIF (variance inflation factors) lebih kecil dari 10 , sehingga dapat disimpulkan bahwa tidak terjadi multikolinearitas dalam model regresi. 
Tabel 5 Hasil Uji Heteroskedastisitas-Glejser

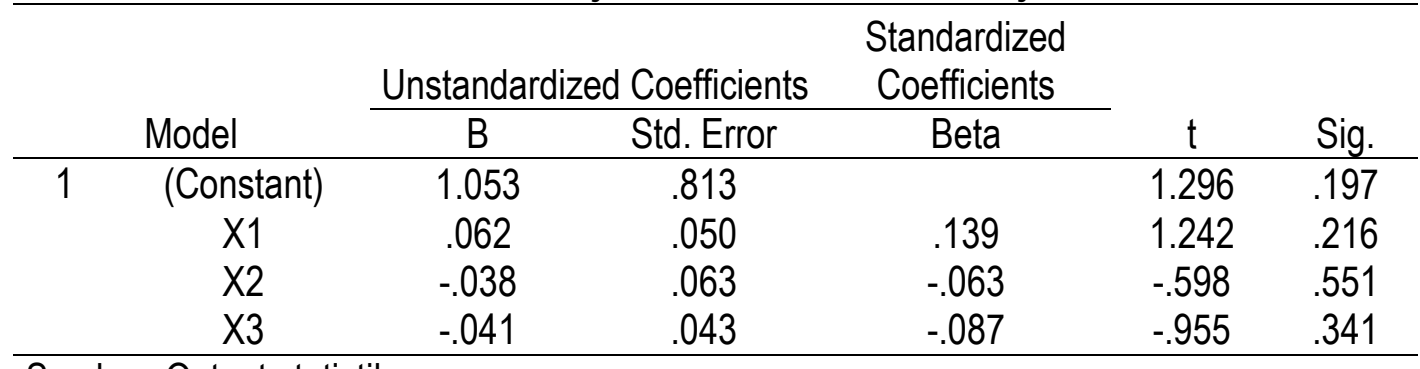

Sumber: Output statistik

Pada tabel di atas dapat dilihat bahwa semua variabel independen (service quality, perceived value, convenience) memiliki nilai sig lebih besar dari 0,05, sehingga dapat disimpulkan tidak terjadi heteroskedastisitas dalam regresi.

Tabel 6 Hasil Uji Autokorelasi

\begin{tabular}{cc}
\hline Model & Durbin - Watson \\
\hline 1 & 1,963 \\
\hline
\end{tabular}

\section{Sumber: Output statistik}

Pada tabel di atas dapat dilihat nilai Durbin Watson adalah 1,963. Nilai tersebut dibandingkan dengan nilai pada tabel DW dimana jumlah sampel $(n)=152$ dan jumlah variabel independen $(k)=3$ serta nilai signifikasi 0,05 . Sehingga didapatkan nilai $d l=1,693$ dan nilai $d u=1,774$. Nilai Durbin-Watson sebesar 1,963 yang berada diantara nilai du $(1,774)<$ $1,963<4$-du (2,226), sehingga dapat disimpulkan bahwa tidak terjadi autokorelasi dalam model regresi.

Tabel 7 Hasil Korelasi (R) dan Koefisien Determinasi (Adjusted R Square)

\begin{tabular}{lllll}
\hline Model & $\mathrm{R}$ & $\mathrm{R}$ Square & $\begin{array}{l}\text { Adjusted } \mathrm{R} \\
\text { Square }\end{array}$ & $\begin{array}{l}\text { Std. Error of the } \\
\text { Estimate }\end{array}$ \\
\hline 1 & $.427^{\mathrm{a}}$ & .182 & .166 & 1.571 \\
\hline Sumber: Output statistik & &
\end{tabular}

Sumber: Output statistik

Pada tabel di atas dapat dilihat nilai koefisien korelasi $(R)$ sebesar 0,427 yang berarti Service Quality $\left(X_{1}\right)$,Perceived Value $\left(X_{2}\right)$, dan Convenience $\left(X_{3}\right)$ memiliki hubungan yang sedang dengan Word Of Mouth $(\mathrm{Y})$ karena terletak diantara 0,40-0,599. Nilai Adjusted $R$ Square sebesar 0,166 yang berarti sebesar $16.6 \%$ variasi variabel word of mouth (Y) dapat dijelaskan oleh variasi variabel Service Quality $\left(\mathrm{X}_{1}\right)$, Perceived Value $\left(\mathrm{X}_{2}\right)$, dan Convenience $\left(X_{3}\right)$ sedangkan sisanya sebesar $83.4 \%$ dijelaskan oleh variasi variabel lain yang tidak terdapat pada penelitian ini. 
Tabel 8 Uji Goodness of Fit

\begin{tabular}{cllllll}
\hline Model & & Sum of & & & & \\
Squares & Df & Mean Square & F & Sig. \\
\hline 1 & Regression & 81.416 & 3 & 27.139 & 10.991 & $.000^{\text {a }}$ \\
& Residual & 365.420 & 148 & 2.469 & & \\
& Total & 446.836 & 151 & & & \\
\hline
\end{tabular}

Sumber: Output statistik

Dalam pendekatan p-value untuk menentukan fit atau tidaknya sebuah model, dilakukan dengan membandingkan hasil $p$ value (sig) dengan alpha (a), dimana jika $p$ value $\leq a$, maka Ho ditolak sehingga dapat disimpulkan model termasuk kriteria fit (Anderson et al. 2014,700). Pada tabel di atas dapat dilihat nilai sig sebesar 0,000 dimana nilai a sebesar 0,05 . Nilai $p$-value $(0,000)<a$ $(0,05)$, maka model termasuk kriteria fit.

Tabel 9 Hasil Analisis Regresi Berganda

\begin{tabular}{|c|c|c|c|c|c|c|}
\hline \multirow[b]{2}{*}{ Model } & & \multicolumn{2}{|c|}{ Unstandardized Coefficients } & \multirow{2}{*}{$\begin{array}{l}\text { Standardized } \\
\text { Coefficients } \\
\text { Beta }\end{array}$} & \multirow[b]{2}{*}{$\mathrm{T}$} & \multirow[b]{2}{*}{ Sig. } \\
\hline & & B & Std. Error & & & \\
\hline 1 & (Constant) & 4.421 & 1.330 & & 3.325 & .001 \\
\hline & $\mathrm{X} 1$ & .199 & .082 & .248 & 2.435 & .016 \\
\hline & $\mathrm{X} 2$ & .049 & .103 & .046 & .478 & .633 \\
\hline & X3 & .187 & .070 & .220 & 2.655 & .009 \\
\hline
\end{tabular}

Sumber: Output statistik

Pada tabel di atas dapat dilihat nilai sig $X_{1}$ sebesar 0,016 dan a sebesar 0,05. Maka nilai $p$-value $(0,016)<a(0,05)$, sehingga dapat disimpulkan bahwa $\mathrm{Ha}$ diterima, artinya terdapat pengaruh Service Quality terhadap Word of Mouth di Bank Mandiri Syariah cabang KCP Jakarta Kedoya dan KCP Jakarta Tanjung Duren. .

Pada tabel di atas dapat dilihat nilai sig $X_{2}$ sebesar 0,633 dan a sebesar 0,05. Maka nilai $p$-value $(0,633)>a(0,05)$, sehingga dapat disimpulkan bahwa $\mathrm{Ha}$ ditolak, artinya tidak terdapat pengaruh Perceived Value terhadap Word of Mouth di Bank Mandiri Syariah cabang KCP Jakarta Kedoya dan KCP Jakarta Tanjung Duren.

Pada tabel di atas dapat dilihat nilai sig $X_{2}$ sebesar 0,009 dan a sebesar 0,05. Maka nilai $p$-value $(0,009)<a(0,05)$, sehingga dapat disimpulkan bahwa $\mathrm{Ha}$ diterima, artinya terdapat pengaruh Convenience terhadap Word of Mouth di Bank Mandiri Syariah cabang KCP Jakarta Kedoya dan KCP Jakarta Tanjung Duren.

\section{PENUTUP}

Berdasarkan hasil analisis dan pembahasan yang dilakukan pada bab IV, maka diperoleh kesimpulan sebagai berikut (1) Terdapat pengaruh Service Quality terhadap Word of Mouth di Bank Mandiri Syariah cabang KCP Jakarta Kedoya dan KCP Jakarta Tanjung Duren, (2) Tidak terdapat pengaruh Perceived Value terhadap Word of Mouth di Bank Mandiri Syariah cabang KCP Jakarta Kedoya dan KCP 
Jakarta Tanjung Duren, (3) Terdapat pengaruh Convenience terhadap Word of Mouth di Bank REFERENCES:
Mandiri Syariah cabang KCP Jakarta Kedoya dan KCP Jakarta Tanjung Duren.

Akroush dan Mahadin 2017. A study of factors affecting word of mouth (WOM) towards Islamic banking (IB) in Jordan. International journal of Emerald.

Anderson, David R., et al. 2014. Statistics for Business and Economics. Canada: South-Western Cengage learning.

Anderson, E.W. 1998, Customer satisfaction and word of mouth, Journal of Service Research, 1(1), 517.

Andy, Sernovitz. 2009. Word of Mouth Marketing: How Smart Companies Get People Talking (Revised Edition). New York: Kaplan Publishing.

Berry, L.L. Seiders dan Grewal, D. 2002. Understanding Service Convenience.

Chaffey, Dave and Fiona Ellis Chadwick. 2012. Digital Marketing Strategy, Implementation, and Practice: Fifth Edition. England: Pearson Education Limited.

Chang, Y.W. and Polonsky, M. J. 2012. The influence of multiple types of service convenience on behavioral intentions: The mediating role of consumer satisfaction in a Taiwanese leisure setting, International Journal of Hospitality Management, 31(1), 107-118.

Grewal, Dhruv and Michael Levy. 2014. Marketing 4th Edition. New York: Hill Companies

Hair, Joseph F., Hult, G. Tomas M., Ringle, Christian M., \& Sarstedt Marko. 2014. Multivariate Data Analysis. England: Pearson Education Limited.

Hogan, J.E., Lemon, K.N. and Libai, B. 2004. Quantifying the ripple: word-of-mouth and advertising effectiveness, Journal of Advertising Research, 45(3), 271-80.

Kotler and Kevin Lane Keller. 2016. Marketing Management. 15th Edition. Pearson Education Limited.

Kotler, Philip and Gary Amstrong. 2014. Principles of Marketing, 15 ${ }^{\text {th }}$ Edition. England: Pearson Education Limited.

Lai, I. K 2005. The Roles of Value, Satisfaction, and Commitment in the Effect of Service Quality on Customer Loyalty in Hong Kong-Style Tea Restaurant. Cornell Hospitality Quarterly, 56(1), 118138. 
